\title{
Correlation between the Antibacterial Ability of Silver Nanoparticle Coated Air Filters and the Dust Loading
}

\author{
Yun Haeng Joe ${ }^{1}$, Wei Ju ${ }^{2}$, Jae Hong Park ${ }^{3}$, Young Hun Yoon ${ }^{4}$, Jungho Hwang ${ }^{{ }^{*}}$ \\ ${ }^{1}$ School of Mechanical Engineering, Yonsei University, Seoul 120-749, Korea \\ ${ }^{2}$ Shanghai Office, Doosan Heavy Industries \& Construction Co., Shanghai City 200-051, China \\ ${ }^{3}$ Department of Occupational and Environmental Health, The University of Iowa, Iowa City, USA \\ ${ }^{4}$ Green Technology Development Office, Korea Environmental Industry \& Technology Institute, Seoul 122-706, Korea
}

\begin{abstract}
This study investigated the correlation between the antibacterial ability of silver nanoparticle air filters with the related dust loading. In addition, a decay equation with which the life cycle of the antibacterial air filters could be predicted was developed. Samples of a HEPA (High Efficiency Particulate Air) filter were coated with an antibacterial agent, silver nanoparticles, which were synthesized via an atmospheric spark discharge method and deposited onto the filters using forced convection flow. A specific amount of dust particles was then blown onto each filter sample. Two kinds of bacteria, Escherichia coli (E. coli), representing Gram-negative bacteria, and Staphylococcus epidermidis (S. epidermidis), representing Gram-positive bacteria, were used in order to examine the antibacterial abilities of the filter samples. The results of the disc diffusion method showed that the dust loading adversely affected the antibacterial efficacy. However, the silver nanoparticle mass density on a filter with a certain amount of dust does increase the antibacterial ability to a certain extent. Finally, decay equations for the decline rates of the antibacterial ability against E. coli and S. epidermidis were obtained with a dimensionless pressure drop across the antibacterial filter samples.
\end{abstract}

Keywords: Silver nanoparticles; Dust loading; Antibacterial; Spark discharge; Disc diffusion method; Decay correlation.

\section{INTRODUCTION}

Heating, ventilation, and air conditioning (HVAC) systems, which are designed and widely operated in order to provide improved air quality in indoor environments, are required not only to ensure acceptable temperature, humidity, and air movement, but also to control various particle pollutants or biological aerosols and to keep humans healthy (Barhate and Ramakrishna, 2007; Yu et al., 2009). Therefore, the filtration of airborne microorganisms is being studied widely using theory and mathematical models based on general particle size distribution (Kowalski et al., 1999). However, resistant bacteria such as Bacillus subtilis can exist on the filter media while maintaining its viability (Wang et al., 1999). In addition, bacteria or mold spores captured in the used air filters can grow and reproduce because the dust deposited in the filters may serve as a source of nutrients if the humidity is sufficient (Schleiginger and Rüden, 1999; Kemp et al., 2001; Maus et al., 2001).

In order to prevent bioaerosol contamination on the air

\footnotetext{
${ }^{*}$ Corresponding author.

E-mail address: hwangjh@yonsei.ac.kr
}

filters, antimicrobial-treated air filters are used. It has been shown that the antimicrobial treatment of fibrous air filters can inhibit the growth of microorganisms on the filters and that the use of antimicrobial agents causes no significant difference in the filtration efficiency for either bioaerosols or inert test aerosols (Foarde and Hanley, 1999). There are primarily two kinds of antibacterial effect assessment methods that are widely used: the disc diffusion method (DDM) and the colony count method (CCM). The CCM is a method for determining the bacterial number by spreading a bacterial solution on an agar plate and counting the bacterial colonies after incubation for approximately 24 hours. The DDM is based on the appearance of a belt-like inhibition zone surrounding the antibacterial-treated specimen, which contacts bacteria placed on the surface of the nutrient agar in a Petri dish, after incubation for approximately 24 hours.

The antimicrobial characteristics of antimicrobial-treated air filters without dust loading have been studied by using the CCM and DDM. Park et al. (2011) reported the antibacterial efficiency of the multi-walled carbon nanotube (MWCNT) deposited glass fiber air filter. They generated Fe nanoparticles for the activation of the air filter using a spark discharger system and then deposited the MWCNT onto the air filters by the chemical vapor deposition (CVD) process. The antibacterial ability of the MWCNT-deposited 
air filter was evaluated using $\mathrm{CCM}$ and it was reported that manufactured filters had high antibacterial ability against $E$. coli. Miaśkiewicz-Peska and Łebkowska (2011) evaluated the antibacterial ability of three kinds of agents: silver nitrate, potassium jodate, and hydrated sodium tetraborate, using DDM. They coated the woven air filters with silver nitrate, which had the best antibacterial performance in their study, as the antibacterial agent and evaluated its antibacterial performance using CCM. Five bacterial strains: Micrococcus luteus, Micrococcus roseus, B. subtilis, Pseudomonas luteola and Pseudomonas putida, were used in their study and it was reported that the presence of an antimicrobial compound in the air filters caused a decrease in the amount of bacteria, which was observed in the case of both the gram-negative and the gram-positive strains. Rantnesar-Shumate et al. (2008) compared the physical capture efficiency (PRE) and the viable bacterial removal efficiency (vBRE) of the novel biocidal (Iodine-treated) filter medium. They reported that there was no discernible difference in the PRE between the iodine-treated and the untreated filters. However, a 2-log enhancement of the vBRE over the PRE was observed against the two bacterial strains of $M$. roseus and $E$. coli. Yoon et al. (2008) studied the antibacterial ability of the silver coated activated carbon fiber (ACF) filters. An ACF filter was coated with silver particles using an electroless deposition method and their antibacterial efficacy against two kinds of bacteria, E. coli, and B. subtillis was evaluated using CCM and DDM. In their study, the inhibition zone increased and the colony ratio decreased with the increments of the amount of coated silver.

Research into the antimicrobial mechanisms of silver nanoparticles or silver ions has been carried out. However, the exact mechanism of action of silver on the microbes is still not known. Possible mechanisms of action of silver nanoparticles and silver ions have been suggested according to the morphological and structural changes found in the bacterial cells upon exposure to silver. It is recognized that the formation of "pits" on E. coli bacteria cell walls by silver nanoparticles significantly increases the permeability of the membranes, resulting in an incapability of the bacterial cells to properly regulate transport through the plasma membrane, ultimately causing cell death (Sondi and SalopekSondi, 2004). A previous mechanistic study on silver ions demonstrated that DNA molecules in bacteria become condensed and lose their replication abilities, accompanied by the inactivation of the bacterial proteins, as a reaction to the denaturation effects of silver ions (Feng et al., 2000). The mechanism of the antibacterial action of silver nanoparticles depends on their size. When silver nanoparticles are small and release many $\mathrm{Ag}+$ ions, the antibacterial activity is dominated by these ions. On the other hand, when relatively large silver nanoparticles are employed with a low rate of $\mathrm{Ag}+$ ion release, the particles themselves also influence the antibacterial action (Sotiriou and Pratsinis, 2010). Metallic silver is sensitive to oxygen, and partially oxidized metallic silver also exhibits antibacterial activities (Lok et al., 2007). The reactive oxygen species (ROS) such as superoxide $\left({ }^{\circ} \mathrm{O}_{2}^{-}\right)$, hydrogen peroxide $\left(\mathrm{H}_{2} \mathrm{O}_{2}\right)$, and highly toxic hydroxyl radical $\left({ }^{\circ} \mathrm{OH}\right)$ can contribute to the antibacterial activity
(Carlson et al., 2008; Neal, 2008; Su et al., 2009; Stevanovic et al, 2012; Xu et al., 2012). It has been reported that ROS are produced when respiratory enzymes are inhibited through the interaction of silver ions with the thiol group of the enzymes. The generated radicals induce the toxic effects related to oxidative stress (Curr et al., 2005; Olmedo et al., 2005; Limbach et al., 2007).

As dust particles deposit on air filters, the dust particles can prevent contact between the silver nanoparticles and the microorganisms, resulting in the decrease in the antimicrobial efficiency and eventually the need for the replacement of the filters. According to a series of qualitative experiments detailed in a report by the American Society of Heating, Refrigerating, and Air-conditioning Engineers (ASHRAE), dust-loaded and non-dust-loaded panel filter pairs with different antimicrobial agents lead to different results in microbial growth tests (Foarde and Hanley, 1999). However, the methodology for the determination of the replacement cycle of used antibacterial air filters has not been investigated. To the best of our knowledge, the decay correlation of the antibacterial ability of antibacterial air filters with dust particles was experimentally investigated for the first time in the study. More specifically, decay equations for the antibacterial ability against two kinds of bacteria $E$. coli and $S$. epidermidis were derived as a function of the pressure drop across the antibacterial filter sample, which could then be applied in order to predict the life cycles of used antibacterial air filters.

\section{METHODS}

\section{Preparation and Characterization of Silver-Deposited HEPA Filter Samples}

Glass fiber HEPA filters (Fabriano $\left.{ }^{\circledR}\right)$ were coated with silver nanoparticles using a spark discharge method, which was described by Byeon et al. (2008) and Tabrizi et al. (2009). The spark discharge method is widely used for generating nanoparticles, because it is simple, easily deliverable, and environmental friendly (Kim and Chang, 2005; Borra, 2006; Simonin et al., 2007). Fig. 1(a) shows the experimental setup for coating filters with silver nanoparticles by using a spark discharger. The system consisted of a test duct, a spark discharge generation system, and a measurement system. A high voltage was applied to a pair of close-set silver electrodes. Dry and clean compressed air was used in order to deliver the generated silver nanoparticles to a sample filter, and its volume flow rate was set at $1.5 \mathrm{~L} / \mathrm{min}$. A filter sample for testing the coating method was installed in the middle of the test duct that was made of acryl. The crosssectional area of the test duct was $4 \times 4=16 \mathrm{~cm}^{2}$, which was the same as the area of the filter sample. The length of the test duct was $1 \mathrm{~m}$. The temperature and relative humidity inside the test duct were maintained at $22.5 \pm 3^{\circ} \mathrm{C}$ and $10 \pm$ $5 \%$, respectively. Two isokinetic stainless steel sampling probes for aerosol sampling were located in the upstream and downstream of the filter media. The size distributions of the silver aerosol nanoparticles upstream and downstream from the filter samples were measured using a scanning mobility particle sizer (SMPS, 3936N22 Custom, TSI Inc., 
(a) Spark discharge and coating test

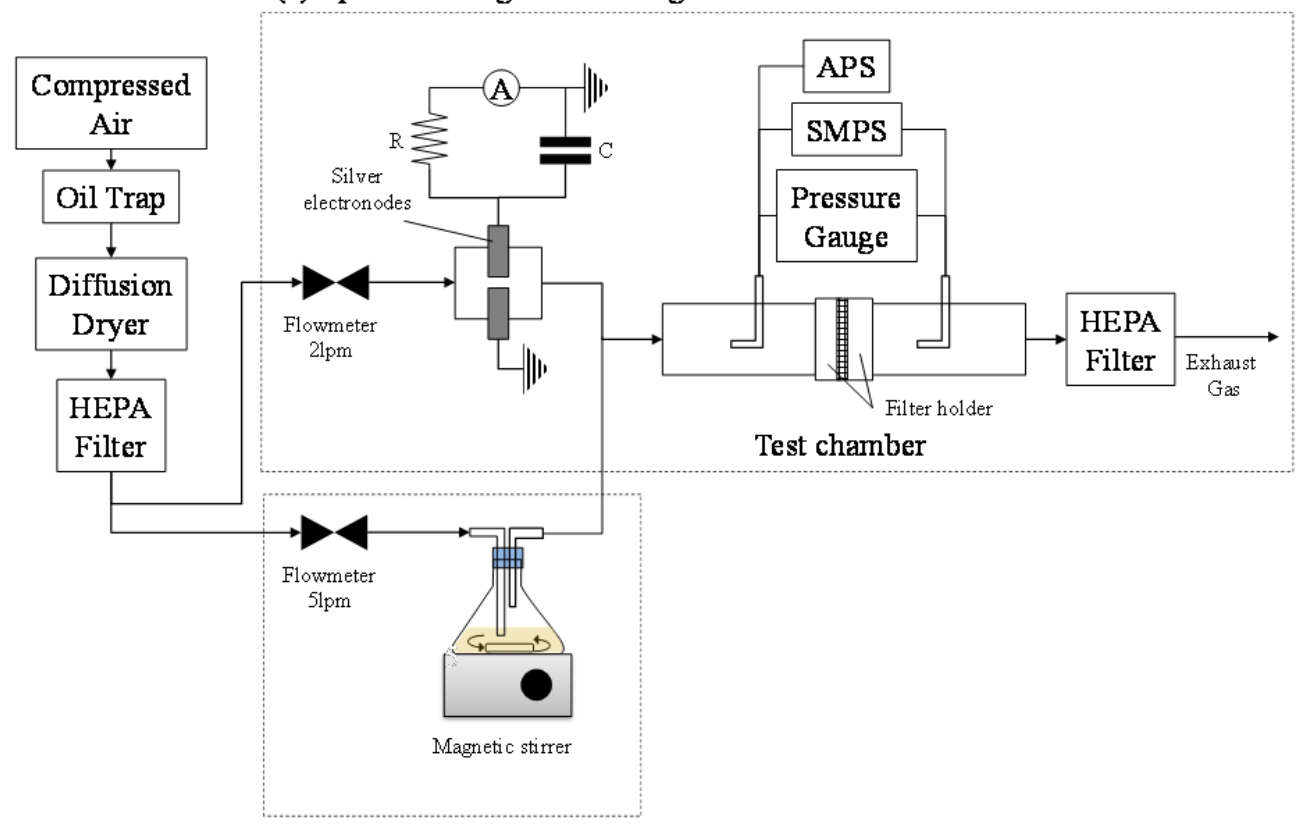

(b) Dust feeding

Fig. 1. Experimental schematic of (a) the coating of silver aerosol nanoparticles, where $2 \mathrm{kV}$ and $1 \mathrm{~mA}$ were used for the spark discharger and (b) dust loading using fly ash generated from a dust feeder.

USA). The SMPS system was composed of a classifier controller (3080, TSI Inc., USA), a differential mobility analyzer (DMA, 3081, TSI Inc., USA), a condensation particle counter (CPC, 3022A, TSI Inc., USA), and an aerosol charge neutralizer (Soft X-ray charger 4530, HCT Co., Ltd., Korea) with a sampling air flow rate of $0.3 \mathrm{~L} / \mathrm{min}$. The SMPS measured the mobility equivalent diameter of the silver aerosol nanoparticles.

The antibacterial filter samples were prepared for coating times of 5, 20, and 60 minutes. The mass areal density $\left(\rho_{M}\right)$ of the coated silver nanoparticles was calculated using Eq. (1) for each coating time:

$$
\begin{aligned}
\rho_{M}\left[\mu \mathrm{g} / \mathrm{cm}^{2}\right]= & \left\{\left(C_{M}^{u p}-C_{M}^{\text {down }}\right)\left[\mu \mathrm{g} / \mathrm{cm}^{3}\right] \times \dot{Q}\left[\mathrm{~cm}^{3} / \mathrm{min}\right]\right. \\
& \times t[\min ]\} / A\left[\mathrm{~cm}^{2}\right]
\end{aligned}
$$

where $\dot{Q}$ is the carrier gas flow rate, $A$ is the effective area of the filter sample, and $C_{M}$ is the total mass concentration of the silver aerosol nanoparticles. The superscripts "up" and "down" refer to the upstream and downstream locations of the filter samples, respectively. Table 1 summarizes the various areal densities for the different coating times used in the experiments.

Before the silver aerosol nanoparticles were coated, each filter sample was sterilized in an autoclave at $121^{\circ} \mathrm{C}$ and $0.1 \mathrm{MPa}$ for approximately 60 minutes. The evolution of the silver nanoparticle dendrites on the filter fibers was observed using a field emission scanning electron microscope (FESEM; JSM-6500F, JEOL, Japan). The coated filter sample was then characterized using X-ray photoelectron spectroscopy (XPS; ESCALAB 220i-XL, VG scientific instrument, USA) and energy dispersive X-ray spectroscopy
(EDS; EX-23000BU, JEOL, Japan).

\section{Dust Loading Using Test Dust}

Dust loading of each silver-deposited filter sample was necessary in order to simulate real-world conditions. In the Begum et al. (2006) study, it was shown that the primary components of the atmospheric particles were $\mathrm{Si}$ and metallic (such as $\mathrm{Al}, \mathrm{Fe}$ ) compounds. In this study, we used Arizona test dust, which consisted of $68 \%$ to $76 \%$ $\mathrm{SiO}_{2}, 10 \%$ to $15 \% \mathrm{Al}_{2} \mathrm{O}_{3}$, and $2 \%$ to $5 \% \mathrm{Fe}_{2} \mathrm{O}_{3}$. The schematic of the experimental setup is shown in Fig. 1(b). The test dust was generated via a dust feeder consisting of an Erlenmeyer flask and a magnetic stirrer. Compressed air was blown into the dust feeder at a volumetric flow rate of $5 \mathrm{~L} / \mathrm{min}$, which carried test dust particles into the test chamber. An aerodynamic particle sizer (APS; 3321A, TSI, USA) and an SMPS system were used in order to measure the size distribution of the test dust. Since the SMPS system measures particles with sizes ranging from 0.0025 to $1.0 \mu \mathrm{m}$ according to their mobility equivalent diameter and the APS measures particles from 0.5 to $20 \mu \mathrm{m}$ according to their aerodynamic diameter using a double-crest optical system, the following equation was used to convert the mobility diameter, $d_{m}$, into the aerodynamic diameter, $d_{a}$ (Park et al., 2003):

$$
d_{a}=d_{m} \times \sqrt{\left(\frac{\rho_{p}}{\chi}\right) \times\left(\frac{C_{c, m}}{C_{c, a}}\right)}
$$

where $\rho_{p}$ is the particle density and $\chi$ is the dynamic shape factor. $C_{c, m}$ and $C_{c, a}$ are the Cunningham slip correction factors corresponding to $d_{m}$ and $d_{a}$, respectively. 
Table 1. Experimental conditions for coating filter samples with silver nanoparticles.

\begin{tabular}{ccccc}
\hline $\begin{array}{c}\text { Coating time } \\
t[\mathrm{~min}]\end{array}$ & $\begin{array}{c}\text { Total concentration } \\
C_{N}\left[\# / \mathrm{cm}^{3}\right], C_{M}\left[\mu \mathrm{g} / \mathrm{cm}^{3}\right]\end{array}$ & $\begin{array}{c}\text { Volume flow rate } \\
Q\left[\mathrm{~cm}^{3} / \mathrm{min}\right]\end{array}$ & $\begin{array}{c}\text { Effective area } \\
A\left[\mathrm{~cm}^{2}\right]\end{array}$ & $\begin{array}{c}\text { Mass areal density } \\
\rho_{M}\left[\mu \mathrm{g} / \mathrm{cm}^{2}\right]\end{array}$ \\
\hline 5 & & & & 0.27 \\
20 & $\sim 1.92 \times 10^{7}, \sim 566.7$ & 1500 & $4 \times 4=16$ & 1.06 \\
60 & & & & 3.19 \\
\hline
\end{tabular}

In order to control the amount of dust loading, the pressure drops between the air upstream and downstream of the filter samples were measured using a differential pressure gauge (Magnehelic ${ }^{\circledR}$ series 2000, DWYER Instrument Inc., USA). The measured pressure drop data were compared with the theoretical predictions carried out using the following equation (Brown, 1993):

$$
\begin{aligned}
& \Delta \mathrm{P}=4 \mu \alpha L u_{0}(1+1.996 K n) / 0.25 d_{f}^{2}\{-0.5 \ln \alpha-0.75 \\
& \left.+\alpha-\frac{\alpha^{2}}{4}+1.996 K n\left(-0.5 \ln \alpha-0.25+\frac{\alpha^{2}}{4}\right)\right\}
\end{aligned}
$$

where $\alpha$ is the filter solidity, $\mathrm{L}$ is the depth of the filter, $\mu$ is the dynamic viscosity of air, $d_{f}$ is the diameter of the glass fiber, and $K_{n}$ is the Knudsen number. The face velocity at the filter fibers $\left(u_{0}\right)$ is defined as $U /(1-\alpha)$, where $U$ is the face velocity at the test chamber. The solidity of the filter was calculated with the following equation: $\alpha=\alpha^{\prime}+\alpha_{d u s t}$, where $\alpha^{\prime}$ is the filter solidity without dust loading. It can be calculated by using $\alpha^{\prime}=M_{f} /\left(\rho_{f} A_{f} L\right)$, where $M_{f}$ is the filter mass, $\rho_{f}$ is the glass fiber density, and $A_{f}$ is the filter area. $\alpha_{\text {dust }}$ is the solidity added by the dust loading and is calculated by using the following equation: $\alpha_{d u s t}=M_{\text {dust }} /\left(\rho_{\text {dust }} A_{f} L\right)$, where $M_{\text {dust }}$ is the mass of the dust particles and $\rho_{\text {dust }}$ is the dust particle density. The masses of the filter before and after dust loading were measured using an electronic precision balance (AR2140, OHAUS Corp., USA). The filter fiber diameter was measured by using the FESEM image. The results for the specifications of the filter are listed in Table 2.

\section{Antibacterial Tests}

Two kinds of bacteria were selected for the antibacterial tests: E. coli (ATCC 11775), and S. epidermidis (ATCC 14990). Both kinds of bacteria were suspended in liquid broth $(\mathrm{BD} \AA$ DifcoTM). After overnight incubation at a temperature of $37^{\circ} \mathrm{C}$, the grown bacterial solutions were diluted with nutrient broth to an optical density (O.D.) of 0.002 , which was measured using a photospectrometer (Libra S12, Biochrom Ltd., UK) when the wave length was $600 \mathrm{~nm}$. The numbers of bacterial cells in the solutions of E. coli and $S$. epidermidis were approximately $2.7 \times 10^{6}$ and $4.5 \times 10^{4}$ colony forming units $(\mathrm{CFU}) / \mathrm{ml}$, respectively. The $100 \mu \mathrm{L}$ bacterial solution was spread onto the surface of the agar plate which contained $5 \mathrm{ml}$ nutrient agar in a 50 $\times 15 \mathrm{~mm}$ Petri dish. The coated filter samples were cut off into circular shape, $1 \mathrm{~cm}$ in diameter, and each of the samples was placed on the surface of the agar. After overnight incubation at $37^{\circ} \mathrm{C}$, the inhibition zone widths were measured using an Absolute Digimatic caliper (CD-20CP, 500 series, Mitutoyo Corp., Japan), with an accuracy of $0.01 \mathrm{~mm}$. Four different locations (in the 3, 6, 9, and 12 o'clock directions) around each filter sample were measured independently and the average values were calculated. The experiments were repeated three times.

\section{RESULTS AND DISCUSSION}

\section{Preparation and Characterization of Silver-Deposited HEPA Filter Samples}

For the conditions of $2 \mathrm{kV}$ and $1 \mathrm{~mA}$ that were employed for the spark discharger, the mode diameter of the generated silver nanoparticles was approximately $16 \mathrm{~nm}$ and the geometric standard deviation was 1.43 . The number and mass concentrations of the silver nanoparticles were $1.92 \times$ $10^{7} \mathrm{H} / \mathrm{cc}$ and $567 \mu \mathrm{g} / \mathrm{cc}$, respectively. Filtration tests were carried out on this upstream aerosol flow. The penetration, $\bar{P}$, was calculated using the following equation: $\bar{P}=$ $C_{N}^{\text {down }} / C_{N}^{u p}$ where $C_{N}$ is the total number concentration of silver aerosol nanoparticles. Fig. 2 shows an FESEM image of the silver deposited glass fibers (coating time $=60 \mathrm{~min}$ ). Nanoparticle dendrites were developed on the glass fiber. The size of the nanoparticle dendrites was approximately $20 \mathrm{~nm}$, which matched the value from the SMPS data. The components of the nanoparticles on the glass fiber were analyzed by EDS analysis, which showed that the coating species were primarily silver compounds. The ZAF (atomic number, absorption and fluorescence correction) method was used for quantitative analysis. Fig. 3 shows that the mass and atomic number fraction of $\mathrm{Ag}$ in the treated filter samples increased as the coating time increased. Fig. 4(a) shows the XPS spectrum obtained from the silver nanoparticle-coated filter. For XPS analysis, we set the pass energy of the survey scan and the detail scan to $50 \mathrm{eV}$ and $20 \mathrm{eV}$, respectively, and we used the C-1s peak (285 eV) for orbital matching. The peaks of the spectrum shown in Fig. 4(a) arise from the Ag core-level, along with the spectral lines of O-KL, O-1s, $\mathrm{C}-1 \mathrm{~s}, \mathrm{Si}-2 \mathrm{~s}$, and Si-2p. The high resolution XPS Ag-3d spectrum is shown in Fig. 4(b). The binding energy (BE) values of $\mathrm{Ag}-3 \mathrm{~d}_{3 / 2}$ and $\mathrm{Ag}-3 \mathrm{~d}_{5 / 2}$ were $374.7 \mathrm{eV}$ and 368.8

Table 2. Specifications of the filter.

\begin{tabular}{ccccc}
\hline $\begin{array}{c}\text { Filter sample Area }\left(A_{f}\right) \\
{\left[\mathrm{cm}^{2}\right]}\end{array}$ & Material & $\begin{array}{c}\text { Fiber diameter }\left(d_{f}\right) \\
{[\mu \mathrm{m}]}\end{array}$ & $\begin{array}{c}\text { Filter sample thickness }(L) \\
{[\mathrm{cm}]}\end{array}$ & $\begin{array}{c}\text { Solidity of dust } \\
\text { unloaded filter }\left(\alpha^{\prime}\right)\end{array}$ \\
\hline $4 \times 4$ & Glass fiber & 2.7 & 0.07 & 0.09 \\
\hline
\end{tabular}




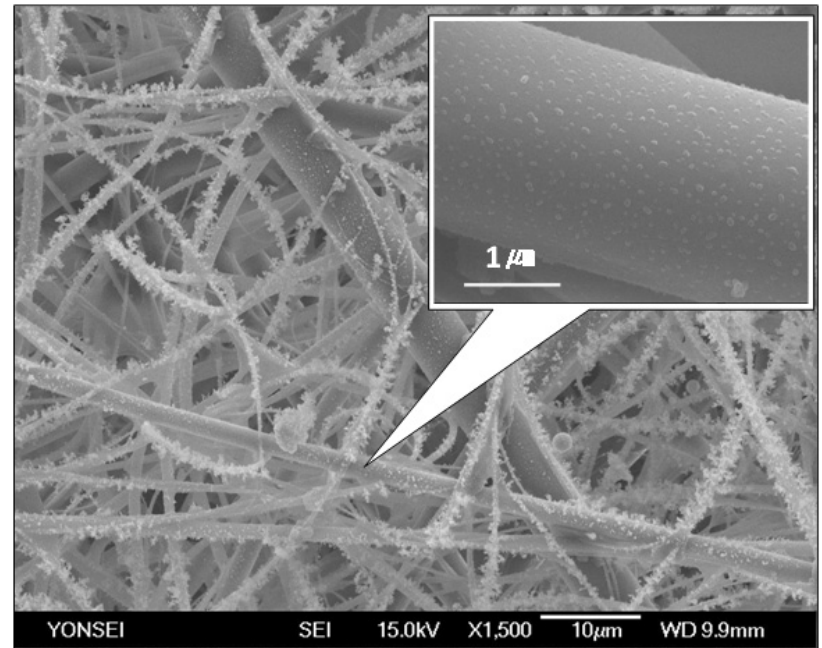

Fig. 2. FESEM photograph of the silver-deposited HEPA filter with no dust loading (coating time is $60 \mathrm{~min}$ ).

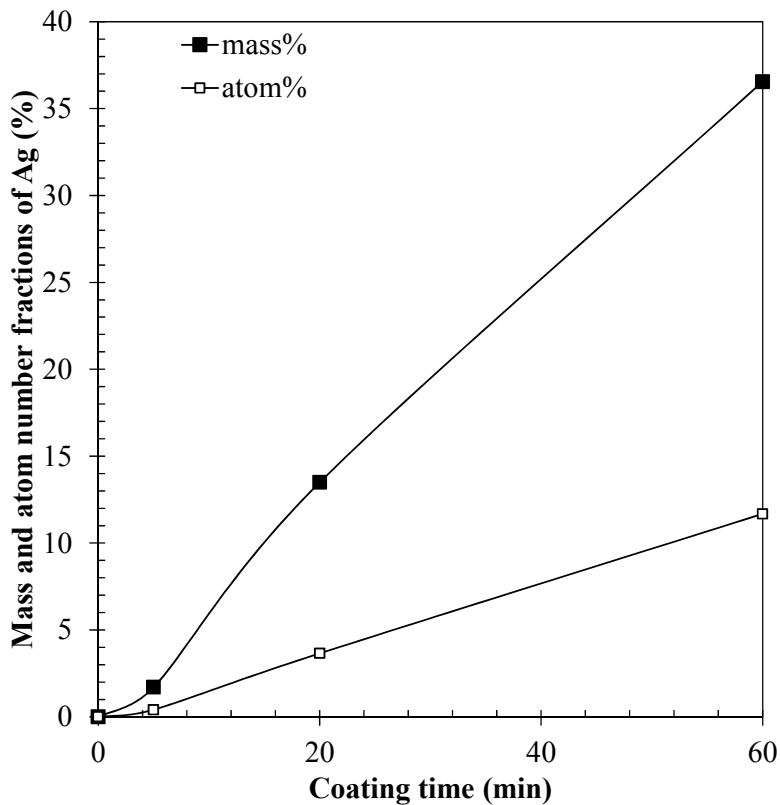

Fig. 3. Analysis results of coating species by EDS.

$\mathrm{eV}$, respectively. The BE value of the silver nanoparticles increased with the decreasing size of the particle (Shin et $a l ., 2004)$ and it was reported that the BE values of the 16 $\mathrm{nm}$ silver nanoparticles were $375 \mathrm{eV}$ at $\mathrm{Ag}-3 \mathrm{~d}_{3 / 2}$ and 368.8 $\mathrm{eV}$ at $\mathrm{Ag}-3 \mathrm{~d}_{5 / 2}$ (Shanmugam et al., 2006). The BE values, which were measured in this study, were in good agreement with those of Shanmugam et al. (2006).

\section{Dust Loading Using Test Dust}

Fig. 5 shows the size distribution of the test dust. The mode diameter of the generated test dust was approximately $4 \mu \mathrm{m}$ and the geometric standard deviation was 1.9. The number and mass concentrations of the test dust were 9.41 $\times 10^{2} \# / c c$ and $3.01 \times 10^{4} \mu \mathrm{g} / \mathrm{cc}$, respectively. Fig. 6 shows an FESEM image of the silver deposited glass fibers with the test dust. The size of the dust particles ranged from approximately 1 to $5 \mu \mathrm{m}$. This wide range of particle sizes resulted in the large geometric standard deviation of the generated test dust.

Pressure drops across different test filter media were measured for various flow rates of clean air. The data are summarized in Fig. 7. For any flow rate, the pressure drops increased as the dust loading amount increased. However, the silver nanoparticles coated onto the filter did not have much effect on the pressure drop, regardless of their number densities. As shown in Fig. 2 and Fig. 6, the silver nanoparticles were much smaller than the diameter of the filter fiber. The increase of the solidity induced by the silver nanoparticles was less than $3.04 \times 10^{-7}$ and this solidity increase did not affect any of the pressure drops. However, the size of the dust particles was bigger than the diameter of the filter fiber. Therefore, the increase in the solidity caused by dust particles ranged from 0.004 to 0.056 . These values were enough to disturb the flow inside the filter and change the pressure drop.

\section{Antibacterial Tests}

In order to observe the effects of the dust loading amount on the antibacterial characteristics, various amounts of the test dust were loaded onto filter samples containing silver nanoparticles. The results are graphed and fitted with a linear function in Fig. 8. The inhibition zone became wider when the number density of the silver nanoparticles was higher (corresponding to a longer coating time). No inhibition zone was observed on the control samples, which contained no silver nanoparticles. The results in Fig. 8 show that a greater dust amount per filter (viz., a higher pressure drop) corresponds to a lower antibacterial ability (viz., a narrower inhibition zone width). The disc diffusion method is based on the diffusion of the antimicrobial compound from impregnated discs onto an agar plate, which has previously been incubated with the test organism (McGill et al., 2009). One plausible reason for the inverse relationship between the dust amount and the inhibition zone width is that the Ag nanoparticles and Ag ions didn't diffuse thoroughly because the dust on the filter blocked the contact between the Ag nanoparticles and the agar plate. 

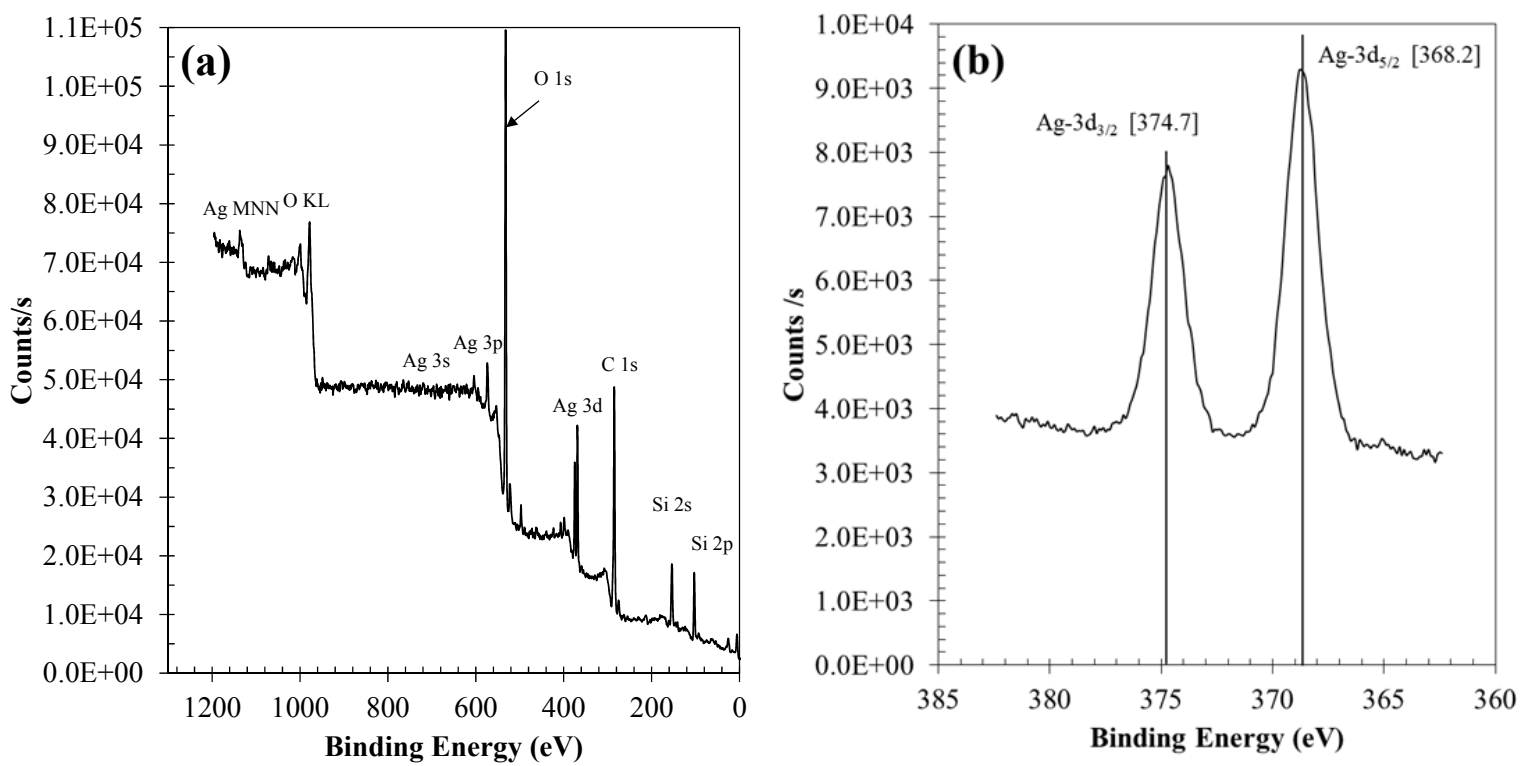

Fig. 4. Analysis results of coating species by XRS: (a) XPS spectrum (pass energy: $50 \mathrm{eV}$, step size: 1eV) and (b) high resolution XPS Ag-3d peaks (pass energy: $20 \mathrm{eV}$, step size: $0.1 \mathrm{eV}$ ).

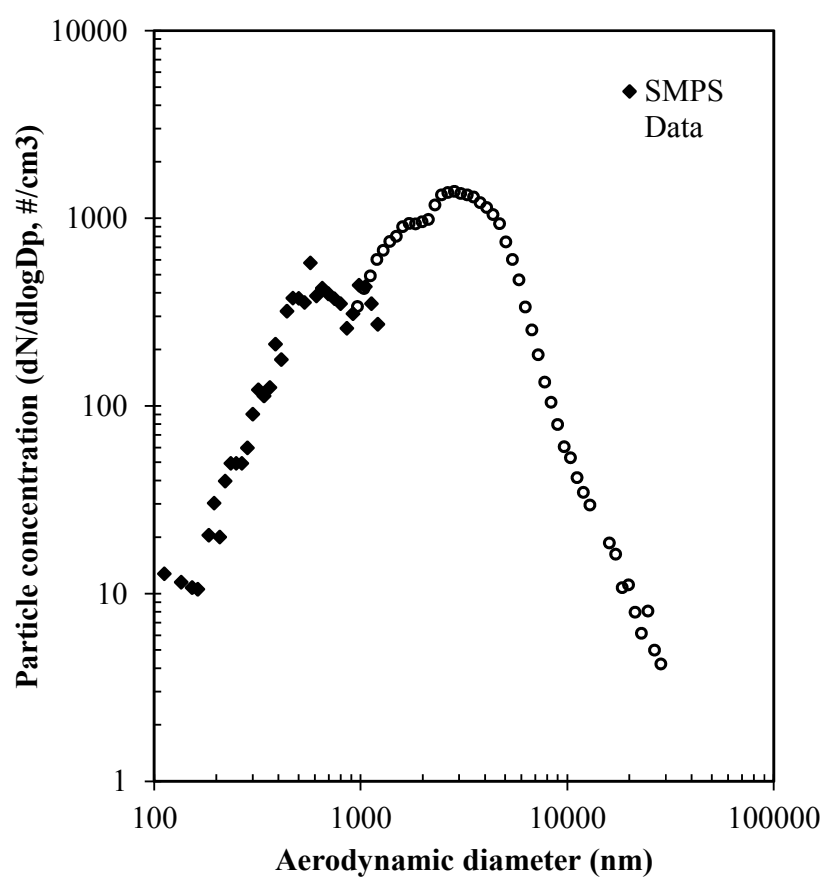

Fig. 5. Size distribution of fly ash used for dust loading.

When the dust loading amount was approximately 0.005 $\mathrm{g} / \mathrm{cm}^{2}$ of the filter surface area and the coating mass density of the silver nanoparticles was $0.27 \mu \mathrm{g} / \mathrm{cm}^{2}$ of the filter surface area, then the inhibition zone diameter of the filter samples containing the silver nanoparticles was approximately $60 \%$ of that measured in the case of no dust loading as is shown in Fig. 8(a). However, the inhibition zone diameter increased to approximately $92 \%$ of that measured in the case of no dust loading when the coating mass density of the silver nanoparticles increased to 3.19 $\mu \mathrm{g}$ per $\mathrm{cm}^{2}$ of the filter surface area.
The silver nanoparticle number density of a filter containing a certain dust amount is an important factor in the antibacterial ability: the more silver nanoparticles that are coated onto a filter, the higher the antibacterial ability becomes. The y-intercept in the fitted linear function reflects the antibacterial efficacy of the unloaded dust filter and this value in the case of $E$. coli was lower than the one in the case of $S$. epidermidis for any amount of silver coating. The absolute value of the slope of the fitted linear function can reflect the sensitivity of the antibacterial efficacy to the loaded dust amount. The absolute values of the slope in the case of $E$. coli were smaller than those in the case of $S$. epidermidis for all silver coated amounts. In our previous study, it was reported that Gram-positive bacteria are more sensitive than Gram-negative bacteria to the silver nanoparticles (Yoon et al., 2007).

In this study we define two dimensionless parameters in order to generalize the relationship between the pressure drop due to dust loading and the antibacterial ability, since the pressure drop is affected by the dust amount as shown in Fig. 7. The dimensionless pressure drop, $\kappa$, is defined as $\kappa=\left(P-P_{0}\right) / P_{0}$ where $P$ and $P_{0}$ are the pressure drops with dust loading and with no dust loading, respectively. The decline in the rate of the antibacterial ability, $\phi$, is defined as $\phi=W / R_{f}$, where $W$ is the inhibition zone width with dust loading and $R_{f}$, is the radius of the filter sample, which was cut to $0.5 \mathrm{~cm}$ in the current study.

Fig. 9 shows the trend lines of the decline rates of the antibacterial ability against $E$. coli and $S$. epidermidis along with the dimensionless pressure drop across the antibacterial filter samples containing silver nanoparticles and dust particles. The empirically fitted equation for each trend line is listed. From the data in this study, we suggest that the relationship between $\kappa$ and $\phi$ for a certain antibacterial filter can be empirically expressed as the general solution of the natural decay equation, $d \phi / d \kappa=-a \phi$, as follows: 


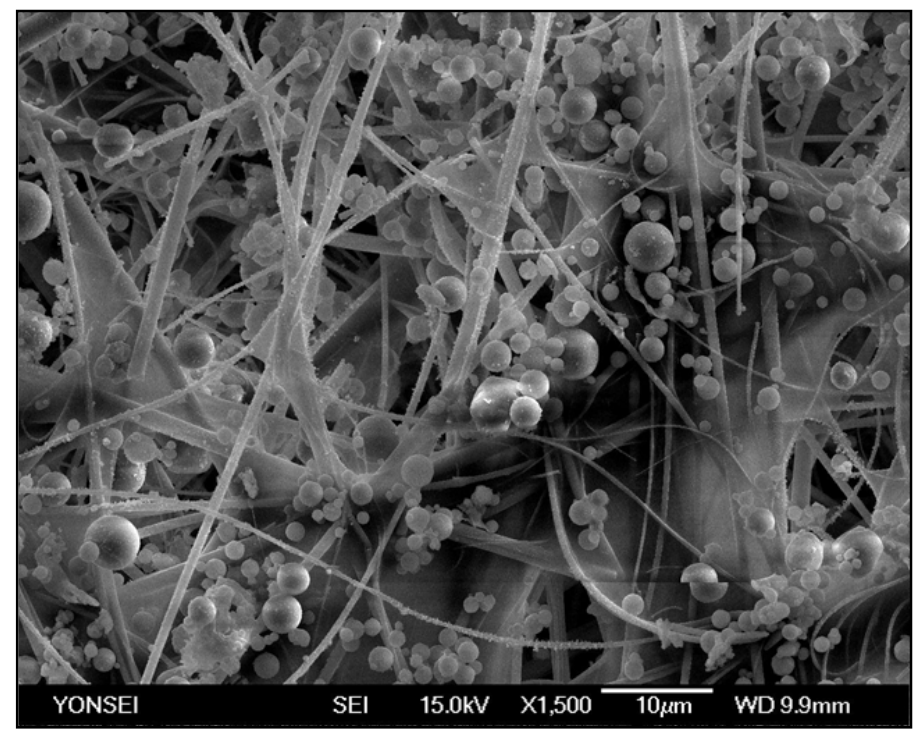

Fig. 6. FESEM photograph of the silver-deposited HEPA filter with dust loading.

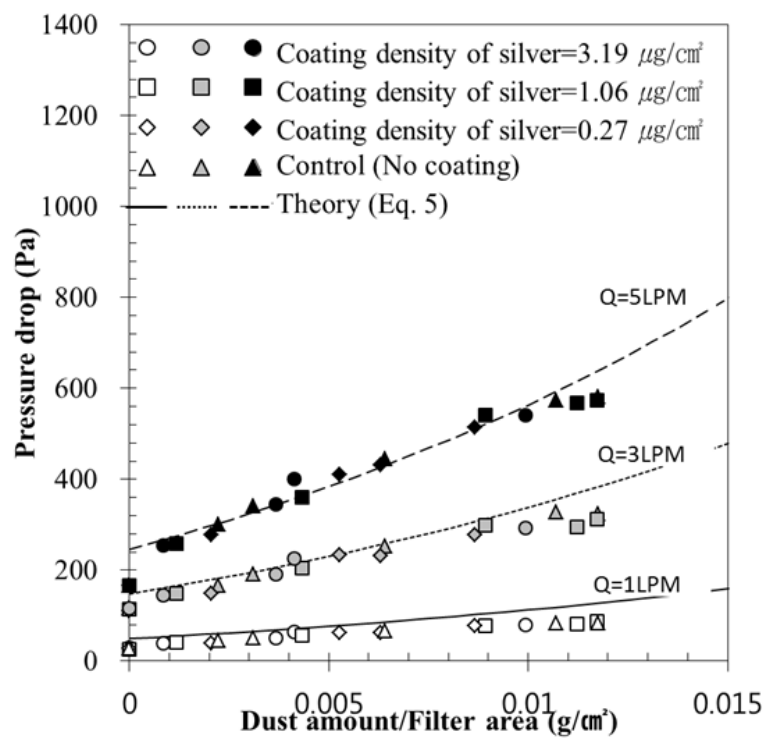

Fig. 7. Pressure drop along with the dust amount.

$\phi=\phi_{0} \exp (-a \kappa)$

where $\phi_{0}$ is the decline rate of the antibacterial ability without dust loading, and the coefficient $a$ is the decay constant depending on the operating conditions, such as the size of the filter as well as the species and amount of bacteria. In this study, we calculated the decay constant $a$ using the following linear equation

$a=a^{\prime} M_{A g}+b^{\prime}$

where $a^{\prime}$ and $b^{\prime}$ are fitting coefficients, and $M_{A g}$ is the areal mass density of the coated silver nanoparticles in $\mu \mathrm{g} / \mathrm{cm}^{2}$. For $E$. coli, the coefficients of $a^{\prime}$ and $b^{\prime}$ are $0.1 \mathrm{~cm}^{2} / \mu \mathrm{g}$ and -0.7 (dimensionless), respectively, while $a^{\prime}$ and $b^{\prime}$ for $S$. epidermidis are $0.15 \mathrm{~cm}^{2} / \mu \mathrm{g}$ and -0.8 , respectively.

In this study, we used DDM as the antibacterial performance test. In the DDM, the inhibition zone appears around antibacterial agent (silver nanoparticle in this study) coated specimens, when the antibacterial agent diffuses from the specimen into the agar. The solubility of the agent and its molecular size will affect the size of the inhibition zone. In order for CCM to be used to evaluate the antibacterial efficacy of the antibacterial agent, only deposited bacteria should be detached from the filter. If deposited dust particles are detached from the filter, the antibacterial agent (silver NP) can be directly exposed to liquid media containing bacteria and can react with the bacterial cells. In a real situation where air filters are used, dust particles can deposit on the silver nanoparticles and prevent direct contact between the filtered microorganisms and the silver nanoparticles.

Even though the DDM is a suitable method for preventing overestimation of the antibacterial effect of silver nanoparticles in USED (dust loaded) air filters, which would be caused by the detachment of the dust particles in the case of using CCM, the DDM also has limitations for the modeling of real operating situation air filters and the interaction between the antibacterial agent and bioaerosols. These limitations are due to the fact that DDM does not simulate what will transpire on a filter when it is contaminated with a bacterial species in aerosol form. In addition, it is difficult to indicate the total amounts of microbes present in the culturing assay using DDM.

In our future studies, experiments will be needed to make the reported data applicable to the activity of antimicrobial agents on filters, such as correlation experiments linking the disc diffusion method to simulated in-use conditions. Experiments will also be needed to study ambient bioaerosols under various operating conditions for air filters, such as temperature and humidity.

\section{CONCLUSIONS}

The antibacterial ability of a silver nanoparticle-coated HEPA filter was evaluated with various amounts of dust 

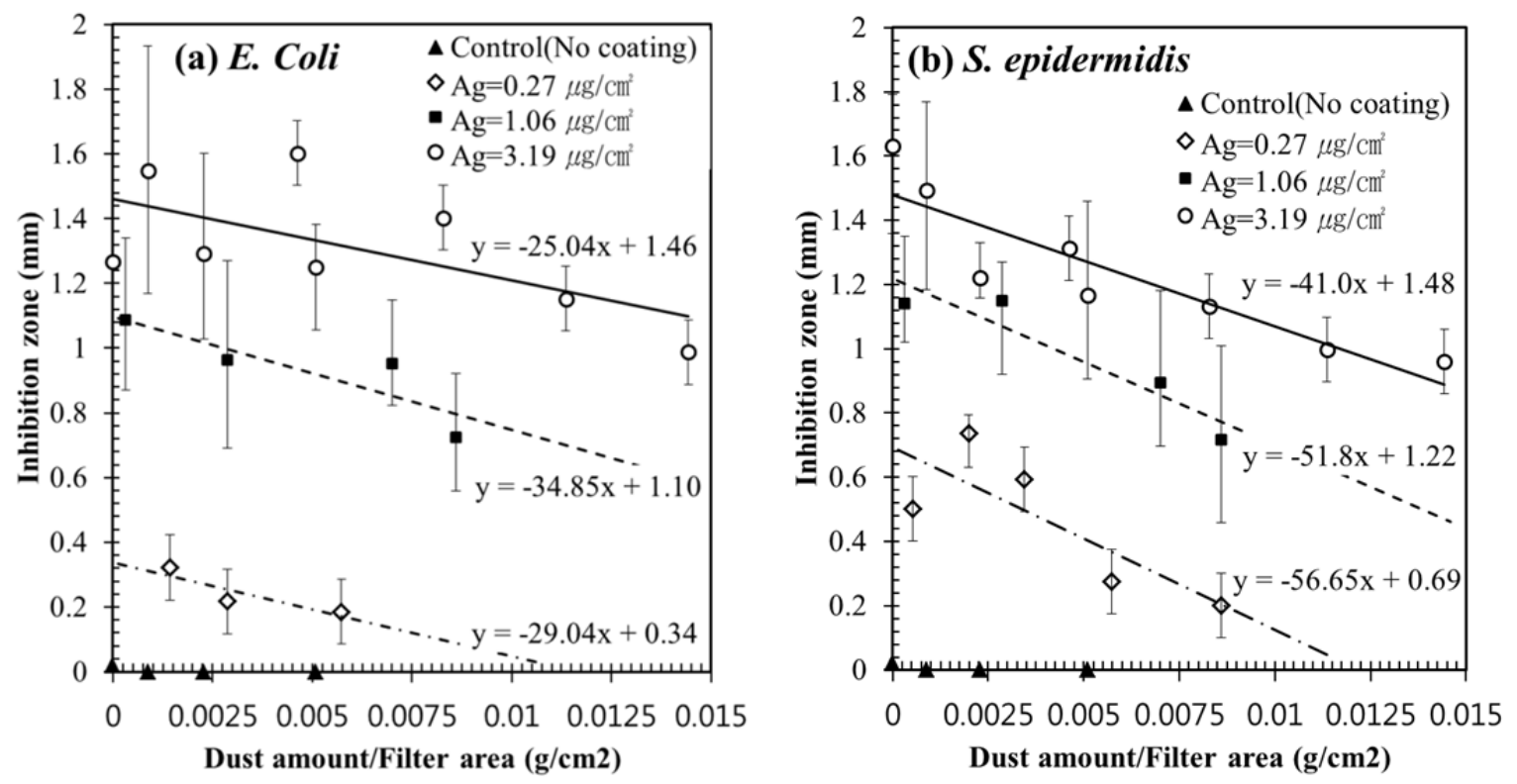

Fig. 8. Inhibition zone width against (a) E. coli and (b) S. epidermidis along with the amount of silver nanoparticles and the dust amount per filter area.
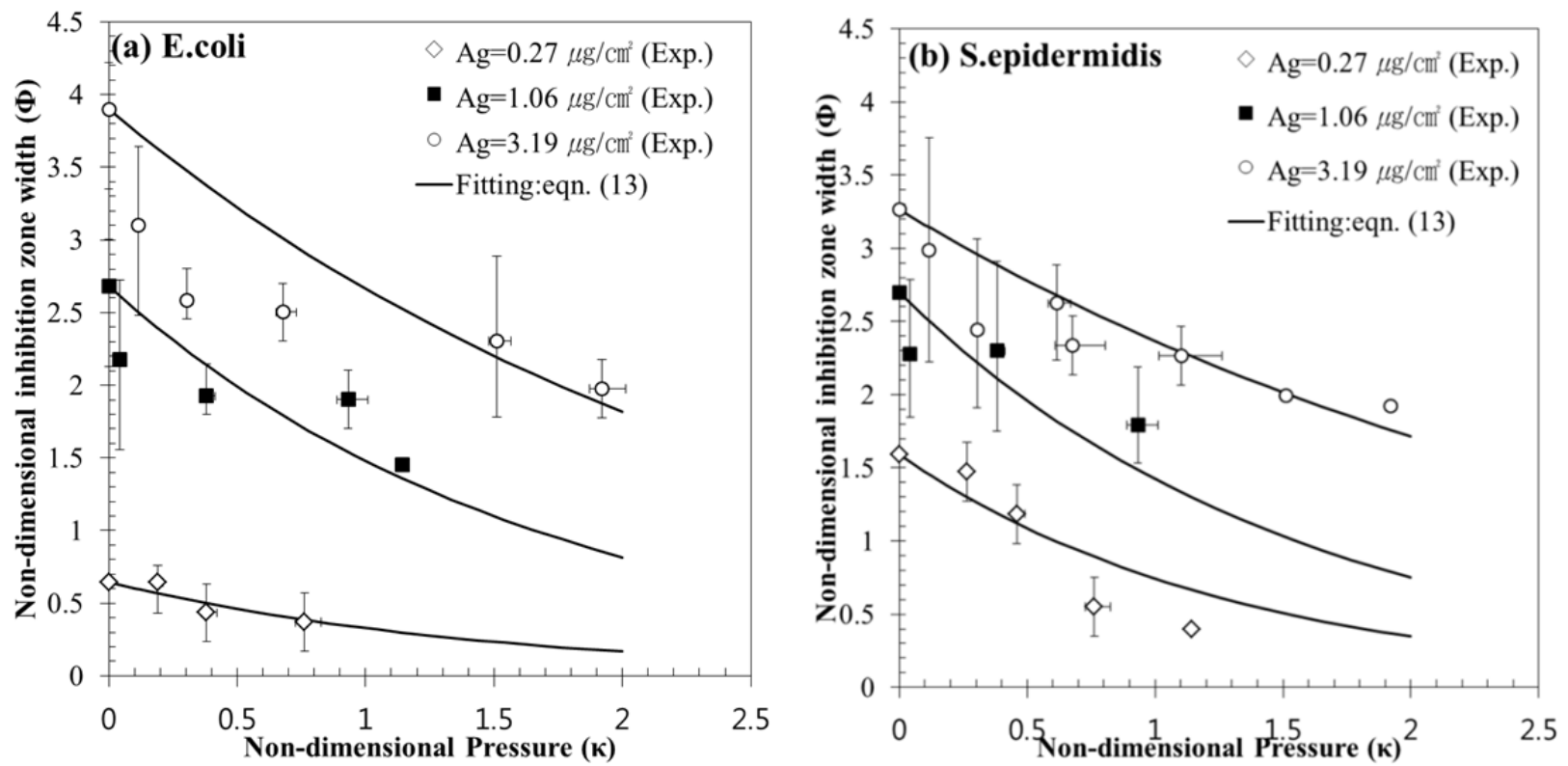

Fig. 9. Trends in the decline rate of the dimensionless inhibition zone width against $E$. coli and $S$. epidermidis along with the dimensionless pressure drop.

loaded. The pressure drop of the test filter increased. In addition, the antimicrobial activity of the filter decreased as the deposited dust amount on the test filter increased, and the antibacterial ability against each strain of bacteria increased as the areal density of the coated silver nanoparticles increased. The inhibition zone width in the case of $S$. epidermidis decreased more rapidly than that in the case of $E$. Coli. Finally, a decay equation for calculating the decline rates of the antibacterial ability against $E$. coli and $S$. epidermidis with the dimensionless pressure drop for various coated areal densities of silver nanoparticles was proposed. This fitting equation was well-matched with the experimental data. The decay equation proposed in this study can be used as reference data in order to determine the replacement cycle for antibacterial filters according to their operating conditions.

\section{ACKNOWLEDGMENTS}

This research was supported by the Future-based Technology Development Program (Green Nano Technology Development Program) through the National Research Foundation of Korea (NRF) funded by the Ministry of Education, Science and Technology (grant number 20110030206). 


\section{REFERENCES}

Barhate, R.S. and Ramakrishna, S. (2007). Nanofibrous Filtering Media: Filtration Problems and Solutions from Tiny Materials. J. Membr. Sci. 296: 1-8.

Begum, B.A., Biswas, S.K., Hopke, PK. and Cohen, D.D. (2006). Multi-element Analysis and Characterization of Atmospheric Particulate Pollution in Dhaka. Aerosol Air Qual. Res. 6: 334-359.

Borra, J.P. (2006). Nucleation and Aerosol Processing in Atmospheric Pressure Electrical Discharges: Powders Production, Coatings and Filtration. J. Phys. D: Appl. Phys. 39: R19-R54.

Brown, R.C. (1993). Air Filtration: An Integrated Approach to the Theory and Applications of Fibrous Filters, Pergamon Press, New York.

Byeon, J.H., Park, J.H. and Hwang, J. (2008). Spark Generation of Monometallic and bimetallic Aerosol Nanoparticle. J. Aerosol. Sci. 39: 888-896.

Carlson, C., Hussain, S.M., Schrand, A.M., Braydich-Stolle, L.K., Hess, K.L., Jones, R.L. and Schlager, J.J. (2008). Unique Cellular Interaction of Silver Nanoparticles: Sizedependent Generation of Reactive Oxygen Species. $J$. Phys. Chem. B 112: 13608-13619.

Feng, Q.L., Wu, J., Chen, G.Q., Cui, F.Z., Kim, T.N. and Kim, J.O. (2000). A Mechanistic Study of the Antibacterial Effect of Silver Ions on Escherichia coli and Staphylococcus aureus. J. Biomed. Mater. Res. 52: 662-668.

Foarde, K.K. and Hanley, J.T. (1999). Determine the Efficacy of Antimicrobial Treatments of Fibrous air Filters. ASHRAE Trans. 4429(RP-909).

Kemp, P.C., Neumeister-Kemp, H.G., Lysek, G. and Murray, F. (2001). Survival and Growth of Micro-Organisms on Air Filtration Media during Initial Loading. Atmos. Environ. 35: 4739-4749.

Kim, J.T. and Chang, J.S. (2005). Generation of Metal Oxide Aerosol Particles by a Pulsed Spark Discharge Technique. J. Electrostat. 63: 911-916.

Kowalski, W.J., Bahnfleth, W.P. and Whittam, T.S. (1999). Filtration of Airborne Microorganisms: Modelling and Prediction. ASHRAE Trans. 105: 4-17.

Lok, C.N., Ho, C.M., Chen, R., He, Q.Y., Yu, W.Y., Sun, H.Z., Tam, P.K.H., Chiu, J.F. and Che, C.M. (2007). Silver Nanoparticles: Partial Oxidation and Antibacterial Activities. J. Biol. Inorg. Chem. 12: 527-534.

Maus, R., Goppelsroder, A. and Umhauer, H. (2001). Survival of Bacterial and Mold Spores in Air Filter Media. Atmos. Environ. 35: 105-113.

McGill, K., Kelly, L., Madden, R.H., Moran, L., Carroll, C., O'Leary, A., Moore, J.E., McNamara, E., O'Mahony, M., Fanning, S. and Whyte P. (2009). Comparison of Disc Diffusion and Epsilometer (E-test) Testing Techniques to Determine Antimicrobial Susceptibility of Campylobacter Isolates of Food and Human Clinical Origin. J. Microbiol. Methods 79: 238-241.

Miaśkiewicz-Peska, E. and Łebkowska, M. (2011). Effect of Antimicrobial Air Filter Treatment on bacterial Survival. Fibres Text. East. Eur. 19: 73-77.
Neal, A. (2008). What Can Be Inferred from Bacterium-nanoparticle Interactions about the Potential Consequences of Environmental Exposure to Nanoparticles? Ecotoxicology 17: 362-371.

Park, J.H., Yoon, K.Y., Na, H., Kim, Y.S., Hwang, J., Kim, J. and Yoon, Y.H. (2011). Fabrication of a Multiwalled Carbon Nanotube-deposited Glass Fiber Air Filter for the Enhancement of Nano and Submicron Aerosol Particle Filtration and Additional Antibacterial Efficacy. Sci. Total Environ. 409: 4132-4138.

Park, K., Cao, F., Kittelson, D.B. and McMurry, P.H. (2003). Relationship between Particle Mass and Mobility for Diesel Exhaust Particles. Environ. Sci. Technol. 37: 577-583.

Ratnesar-Shumate, S., Wu, C.Y., Wander, J., Lundgren, D., Farrah, S., Lee, J. H., Wanakule, P., Blackburn, M., and Lan M.F. (2008). Evaluation of physical Capture Efficiency and Disinfection Capability of an Iodinated Biocidal Filter Medium. Aerosol Air Qual. Res. 8: 1-18.

Schleiginger, H. and Rüden, H. (1999). Air Filters from HVAC Systems as Possible Source of Volatile Organic Compounds (VOC)-Laboratory and Field Assays. Atmos. Environ. 33: 4571-4577.

Shanmugam, S., Viswanathan, B. and Varadarajan, T.K. (2006). A Novel Single Step Chemical Route for Noble Metal Nanoparticles Embedded Organic-Inorganic Composite Films. Mater. Chem. Phys. 95: 51-55.

Shin, H.S., Choi, H.C., Jung, Y., Kim, S.B., Song, H.J. and Shin, H.J. (2004). Chemical and Size Effects of Nanocomposites of Silver and Polyvinyl Pyrrolidone Determined X-ray Photoemission Spectroscopy. Chem. Phys. Lett. 383: 418-422.

Simonin, L., Lafont, U., Tabrizi, U., Schmidt-Ott, A. and Kelder, E.M. (2007). Sb/O Nano-composites Produced via Spark Discharge Generation for Li-ion Battery Anodes. J. Power Sources 174: 805-809.

Sondi, I. and Salopek-Sondi, B. (2004). Silver Nanoparticles as Antimicrobial Agent: A Case Study on E. coli as a Model for Gram-negative Bacteria. J. Colloid Interface Sci. 275: 177-182.

Sotiriou, G.A. and Pratsinis, S.E. (2010). Antibacterial Activity of Nanosilver Ions and Particles. Environ. Sci. Technol. 44: 5649-5654.

Stevanovic, M.M., SKapin, S.D., Bracko, I., Milenkovic, M., Petkovic, J., Filipic, M. aand Uskokovic, D.P. (2012). Poly(lactide-co-glycolide)/Silver Nanoparticles: Synthesis, Characterization, Antimicrobial Activity, Cyroroxicity Assessment and ROS-inducing Potential. Polymer 53: 2818-2828.

Su, H.L., Chou, C.C., Hung, D.J., Lin, S.H., Pao, I.C., Lin, J.H., Huang, F.L., Dong, R.X. and Lin, J.J. (2009). The Disruption of Bacterial Membrane Integrity through ROS Generation Induced by Nanohybrids of Silver and Clay. Biomaterials 30: 5979-5987.

Tabrizi, N.S., Ullmann, M., Vons, V.A., Lafont, U. and Schmidt-Ott, A. (2009). Generation of Nanoparticles by Spark Discharge. J. Nanopart. Res. 11: 315-332.

Wang, Z., Reponen, T., Willeke, K. and Grinshpun, S.A. (1999). Survival of Bacteria on respirator filters. Aerosol 
Sci. Technol. 30: 300-308.

Xu, H., Qu, F., Xu, H., Lai, W., Wang, Y. A., Aguilar, Z. P. and Wei, H. (2012). Role of Reactive Oxygen Species in the Antibacterial Mechanism of Silver Nanoparticles on Escherichia coli O157:H7. Biometals 25: 45-53.

Yoon, K.Y., Byeon, J.H., Park, J.H. and Hwang, J. (2007). Susceptibility Constants of Escherichia coli and Bacillus subtilis to Silver and Copper Nanoparticles. Sci. Total Environ. 373: 572-575.

Yoon, K.Y., Byeon, J.H., Park, C.W. and Hwang, J. (2008). Antimicrobial Effect of Silver Particles on Bacterial
Contamination of Activated Carbon Fibers. Environ. Sci. Technol. 42: 1251-1255.

Yu, B.F., Hu, Z.B., Liu, M., Yang, H.L., Kong, Q.X. and Liu, Y.H. (2009). Review of Research on Air-conditioning Systems and Indoor Air Quality Control for Human Health. Int. J. Refrig. 32: 3-20.

Received for review, July 20, 2012 Accepted, January 8, 2013 